\title{
The Relationship between Head-Nurse's Managerial Skills and Nurses' Turnover Intention in Private Hospitals
}

\section{Nasiripour AA ${ }^{1}$, Tabibi $\mathbf{S J}^{2}$ and Mokhtari $\mathbf{R}^{3^{*}}$}

${ }^{1}$ Associate Professor, Department of Health Services management, Science and Research Branch , Islamic Azad University, Tehran, Iran

${ }^{2}$ Professor, Department of Health Services management, Science and Research Branch, Islamic Azad University, Tehran, Iran

${ }^{3}$ Science and Research Branch, Islamic Azad University, Tehran, Iran

\begin{abstract}
Background: Nurses' Turnover Intention is one the most important problems of human recourses management in a hospital setting.

Aim: To determine the relationship between head nurses' managerial skills and nurses' turnover intention in private hospitals.

Materials and methods: A sample of 370 nurses were selected from the nurses of private hospitals located in city of Tehran $(\mathrm{N}=10,000)$ using a cluster sampling method. For this purpose, first city of Tehran was divided into 5 different zones (areas) as north, south, east, west and centre. Then three hospitals were randomly selected from each zone (area) and 30 questionnaires were randomly distributed among the nurses in each hospital. The path analysis was used to test the research hypotheses in this study.

Results: The findings indicated that there is a negative relationship between head nurse's managerial skills and nurses' turnover intention of Tehran private hospitals. The path coefficient between technical, human, and perceptional variable with nurses' turnover intention was $(-4.07),(-4.83)$ and $(-2.84)$ respectively.
\end{abstract}

Conclusion: Nursing managerial skill can play a significant role in decreasing nurses' turnover intention.

Keywords: Managerial skills; Nurse; Turnover intention; Hospital

\section{Introduction}

The aims of each organization are the existential philosophy of that organization. There is need to a kind of cooperative endeavor for realizing of those aims. The complicatedness of the collective work has created the systematic management. The efficiency and effectiveness as the two important aims of all organizations require some policies that the managers to adopt. On the other hand, the limitation and inadequacy of the sources and the environmental alterations in different foreign and inland areas and fields determines the worth of management more than before. It is apparent that the establishment and development of the organizations is the consequence of the existence of management and the organization and management are correlative with each other [1].

The management science in its modern way, developed from the beginning of $20^{\text {th }}$ century. Nowadays, the significance of management is not deniable in the success of the organizations. The managers are in charge of applying and utilizing of humane sources for providing of organizational aims. The managers have significant role in the success of the organizations because they determine the direction of the moving of the organization and the manner of mixing of the sources and accomplishment of the missions by deciding about the aims, programs and the operations. The ever-increasing growth and development of the management science has caused appropriate management of the most outstanding organizations in the lattermost places of the world. The assigned credits for training of the managers in the biggest companies in civilized and advanced country is indicative of the the significance and concerns of thses organization for this issue. It is clear that the industrial and civilized world has undrestood that providing of more benefit depnds on more investment in this case [2].

Also, these days, one of the proportional, vital and necessary advantages of the organizations in the competitive and insecure atmosphere is the factor of their management. In the current world, we can hear the name of a manager behind each huge and economical machine. So, efficient and effective management is the guarantor of the success of the organization in achieving to its aims and its guidelines indisputably. In this case, requiring of management - particularly in the universities and scientific centers - is considerable for vital role of this centre in respect of education of trained humane power (force). One of the factors of the continuity of the success of each organization is competence and qualification of the managers in respect of management skills. The efficiency and effectiveness of the managers needs the management skills. In fact, it is possible to realize these aims by applying of them in different positions and situations [3].

The managers who have management and supervising skills increase the contentment and trust of the inferiors to the management as well as their emotional obligation. The managers, who show effective and efficient management and supervising behaviors, create a collection of positive results in the organization. Securing and protection of the health and well-being of the humans is one of the most central right of humans, so nursing services has special place in this system as a ring of the chain of hygienic and medicament affairs. According to the major role of nurse in hygienic and medicament system of the society, the

*Corresponding author: Reyhane Mokhtari, Science and Research Branch, Islamic Azad University, PO Box 14515-775, Tehran, Iran, Tel: +98 21 44869701; E-mail: drnp20@yahoo.com

Received January 17, 2014; Accepted January 23, 2014; Published January 25, 2014

Citation: Nasiripour AA, Tabibi SJ, Mokhtari R (2014) The Relationship between Head-Nurse's Managerial Skills and Nurses' Turnover Intention in Private Hospitals. Health Care Current Reviews 2: 117. doi: 10.4172/2375-4273.1000117

Copyright: (c) 2014 Nasiripour AA, et al. This is an open-access article distributed under the terms of the Creative Commons Attribution License, which permits unrestricted use, distribution, and reproduction in any medium, provided the original author and source are credited. 
relation of the head nurse and nurse is very close because of the type of their activities and is very effective in the manner of accomplishment of their duties. The reason is that the duties of the head nurses can have direct relation with the health and recovery of the patients and making motives for development of efficiency and suitable clinicalnursing services. Also, the existence of different management skills of the head nurses makes necessary motives for the nurses for services. In this case, the organization becomes a proper place for effort and rarely, they think of abandonment of the organization. Therefore, the main objective of the present paper was to determine the relationship between Head nurse's Managerial Skills and nurses' turnover intention in Tehran's private hospitals.

\section{Materials and Methods}

In order to do this research a sample of 450 nurses were selected from the nurses of private hospitals located in city of Tehran $(\mathrm{N}=10,000)$ using a cluster sampling method. For this purpose, first city of Tehran was divided into 5 different zones (areas) as north, south, east, west and centre, and then three hospitals were randomly selected from each zone (area). Total of 450 questionnaires were randomly distributed among the nurses in the selected hospitals- 30 questionnaire in each. The internal consistency of the questionnaire was 0.841 using Cronbach's alpha. The path analysis was used to test the research hypotheses in this study.

\section{Results}

From 450 distributed questionnaires, 396 were returned to the researcher from which 370 were complete, and they are analyzed here.

The findings revealed that $47.6 \%$ of the respondents were male and $52.4 \%$ female. Most of the participants (64.6\%) had 20 to 29 years old, and the rest were older, $80 \%$ of them had a bachelor and $20 \%$ master degree. $27 \%$ had less than one year experience, $12.4 \%$ had 10 or more years of experience (Table 1).

Figure 1 reveals the model, and the path coefficients for the relationship between head nurses managerial skill, and nurses' turnover intention in the investigated hospital. Figure 2 also shows the model and path coefficients regarding the relationship between the head nurses' technical, humane and perceptional skills and nurse turnover intention. The summary of the results of regression model are presented in Table 2 .

As the findings in Table 2 indicate there is a significant relationship between managerial skills of head nurses and nurse turnover intention. Table 2 also shows the path coefficient for three aspects of head nurses managerial skills (technical, humane and perceptional). Single-sample $\mathrm{t}$-test also was done to test if the nurses managerial skill is proper has been used (Table 3).

According to the findings of Table 3 the average of the levels of head nurse's managerial skills is 3.72 which is higher than the average score on the 5 point Likert Scale (i.e. 3). The t value obtained in this regard indicates that the head nurses' managerial skill is at proper level. The same occlusion holds true for three aspects of the head nurses' managerial skill.

The average score of nurses' turnover intention was 2.45 and lower than the average score on the five point Likert scale (i.e. 3). Therefore, the level of nurses' turnover intention in Tehran's private hospitals is low.

\begin{tabular}{|l|l|l|}
\hline Gender & F & $\%$ \\
\hline Male & 176 & 47.6 \\
\hline Female & 194 & 52.4 \\
\hline Total & 370 & 100 \\
\hline Age & $\mathrm{F}$ & $\%$ \\
\hline $20-29$ years & 239 & 64.6 \\
\hline $30-39$ years & 122 & 33 \\
\hline $40-49$ years & 9 & 2.4 \\
\hline Total & 370 & 100 \\
\hline Education & $\mathrm{F}$ & $\%$ \\
\hline Bachelor & 296 & 80 \\
\hline Master Degree & 74 & 20 \\
\hline Total & 370 & 100 \\
\hline Experience in the Organization & $\mathrm{F}$ & $\%$ \\
\hline Less than 1 year & 100 & 27 \\
\hline $1-5$ years & 158 & 42.7 \\
\hline $5-10$ years & 66 & 17.8 \\
\hline $10-15$ years & 37 & 10 \\
\hline $15-20$ years & 9 & 2.4 \\
\hline Total & 370 & 100 \\
\hline
\end{tabular}

Table 1: Demographic Information on the Participants

\begin{tabular}{|l|l|l|l|}
\hline From & To & Standardized Coefficient & P-Value \\
\hline Managerial Skill & Turnover Intention & -0.70 & -0.70 \\
\hline Technical Skill & Turnover Intention & -0.23 & -0.23 \\
\hline Humane Skill & Turnover Intention & -0.33 & -0.33 \\
\hline Perceptional Skill & Turnover Intention & -0.18 & -0.18 \\
\hline
\end{tabular}

Table 2: The Results of the Path Coefficient of the Variable in the Model

\begin{tabular}{|l|l|l|l|l|l|}
\hline Variable & Mean Score & SD & df & t & p-Value \\
\hline $\begin{array}{l}\text { The level of head nurses' } \\
\text { managerial skills of Tehran } \\
\text { private hospitals is proper }\end{array}$ & 3.72 & 0.692 & 369 & 729.39 & 0.000 \\
\hline $\begin{array}{l}\text { The level of head nurses' } \\
\text { technical skills of Tehran } \\
\text { private hospitals is proper }\end{array}$ & 3.46 & 0.800 & 369 & 637.79 & 0.000 \\
\hline $\begin{array}{l}\text { The level of head nurses' } \\
\text { humane skills of Tehran } \\
\text { private hospitals is proper }\end{array}$ & 3.76 & 0738 & 369 & 683 & 0.000 \\
\hline $\begin{array}{l}\text { The level of head nurses' } \\
\text { perceptional skills of Tehran } \\
\text { private hospitals is proper }\end{array}$ & 3.93 & 0.774 & 369 & 647.43 & 0.000 \\
\hline $\begin{array}{l}\text { The level of head nurses' } \\
\text { perceptional skills of Tehran } \\
\text { private hospitals is proper }\end{array}$ & 3.93 & 0.774 & 369 & 647.43 & 0.000 \\
\hline
\end{tabular}

Table 3: t- test Results on Head Nurses' Managerial Skills

\section{Discussion}

According to the findings of the study, the result showed that there is relation between head nurse's managerial skills and decreasing of nurse employees' turnover intention of Tehran private hospitals. The positive (significant, meaningful) and standardized coefficient which were between two variants indicated that head nurse's managerial skills and decreasing of nurse employees ' turnover intention of Tehran private hospitals. These results verify the results of the study of Walls and Peachey [4]. Walls and Peachey considered the relation which is between managerial behaviors and employees' turnover intention in their study. The result showed that there is negative relation between the effective managerial behaviors and voluntary employees' turnover intention. Also, satisfaction of the manager is the reason of decreasing of employees' turnover intention. 
Citation: Nasiripour AA, Tabibi SJ, Mokhtari R (2014) The Relationship between Head-Nurse's Managerial Skills and Nurses' Turnover Intention in Private Hospitals. Health Care Current Reviews 2: 117. doi: 10.4172/2375-4273.1000117

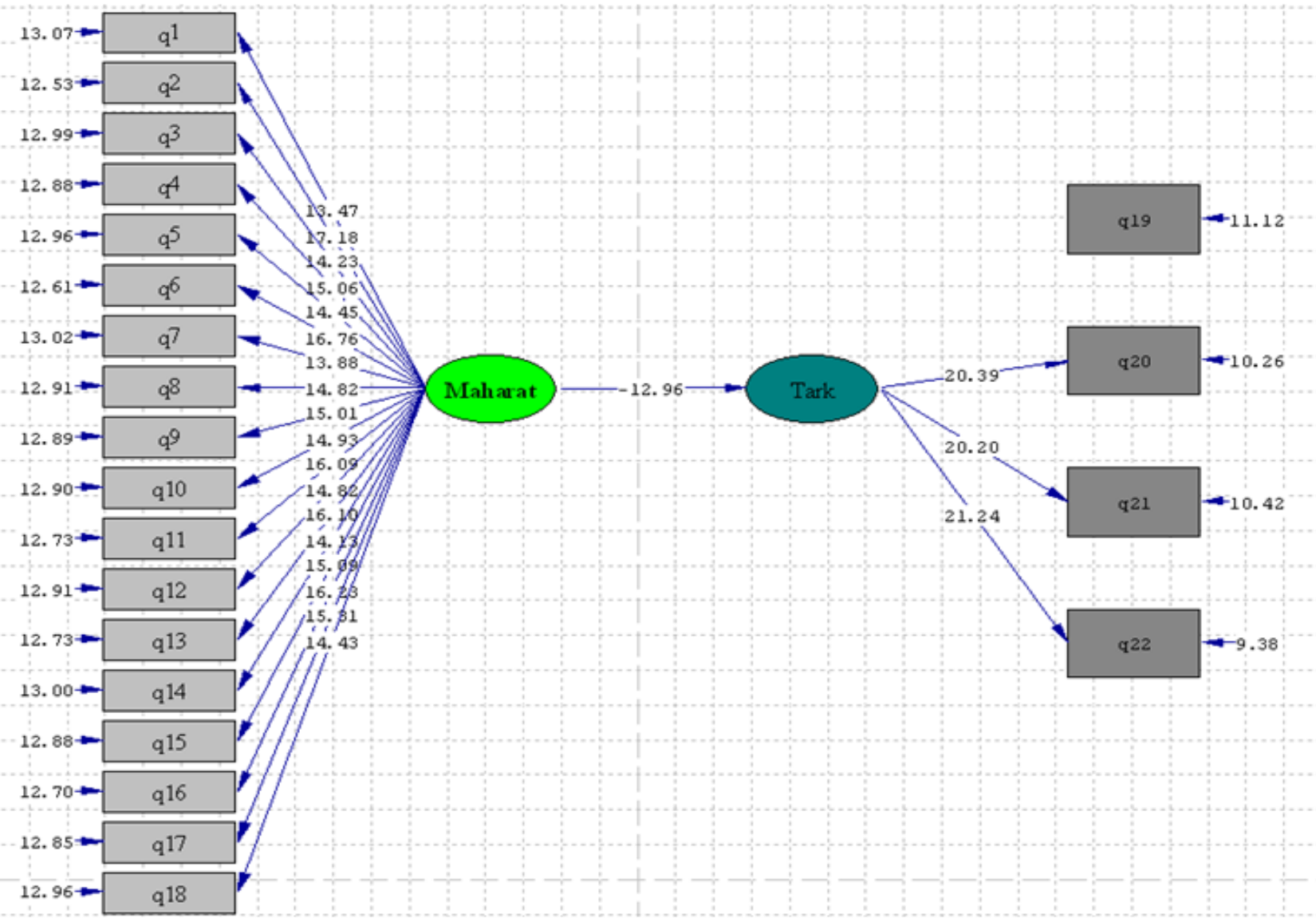

Figure 1: Relationship between head nurse's managerial skills and nurses' turnover intention

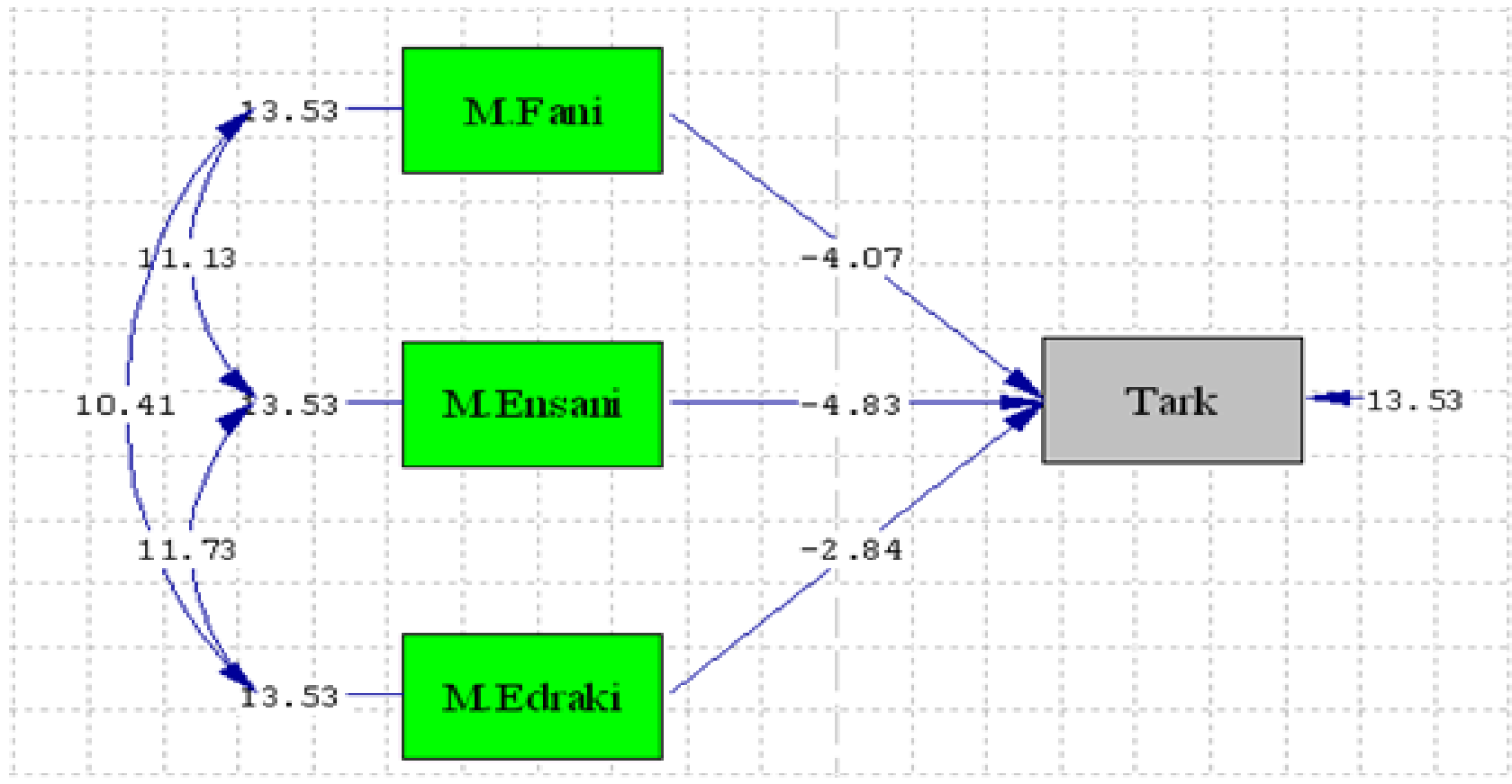

Figure 2: The model and path coefficients for relationship between head nurses' technical, human and perceptional skills with nurse turnover intention. 
The effective manager is the one who can apply and use of 80 to 90 percentages of the abilities of the employees in a proper and humane communication for realizing of the organizational purposes. For being successful and effective, the manager must have specific intrinsic and acquisitive abilities and the technical, humane, perceptional and problem solving abilities. It is clear that the organizational atmosphere, environmental stimulations, the tendencies and the views of the managers are effective in this relation [5].

Also, there was a significant relationship between head nurse's technical skills and decreasing of nurse employees' turnover intention of Tehran private hospitals. The standardized coefficient of the two variants showed that there is relation between head nurse's technical skills and decreasing of nurse employees' turnover intention of Tehran private hospitals. This study results verify the study results of Jalil et al. [6] and Tohfe [7]. Tohfe [7], in his study entitled "the relation of triple managerial skills and utilizing of human sources in electricity Distribution Company of Fars province" considers the relation of triple skills of the managers and utilizing of human sources in electricity Distribution Company of Fars province. The result showed that the technical skills of the managers have priority in regarding to forecasting of utilizing of the employees and the significance of the humane and perceptional skills are in the second and third degrees of importance. Also, according to the achieved results of the study, the humane and perceptional skill of the head nurses as well the technical skills have relationship with nurse employees' turnover intention. Also, effectiveness and efficiency of the mangers needs managerial skills, so shortage of each one of these skills decreases the possibility of the success of the organization as a whole. Therefore, each of these skills is significant for accomplishments of the managerial duties [8].

The level of head nurse's managerial skills of investigated hospitals is higher than the anticipated level. The average of the level of the head nurse's managerial skills was obtained higher than the average level. Therefore, this hypothesis which is based on the suitable level of head nurse's managerial skills of Tehran private hospitals was verified. In other words, the level of head nurse's managerial skills of Tehran private hospitals is appropriate. These results study verify the results researches of Yoosefian [9], Asef zade [10] and Azad [11]. Azad [11] considers the managerial skills and their relation with the proceeds of the general managers of Ilam Province in his study entitled "the study of managerial skills and its relation with the proceeds of the general managers of Ilam province". The major hypothesis of this study considers the relation which is between the degree of managerial skills of the managers and their proceeds. This hypothesis was verified after the test. It considered the relation of the factors such as governmental employment record and the age of the mangers and the proceeds of the managers. The result was that there was relation between the age and the governmental employment record and the proceeds of the managers.

The managerial skill is one of the main parts of the collection of the tools of a successful manager. It is clear that the skills and the experiences of the managers are determined by their learning abilities and changes according to the environmental alterations [12].

The level of head nurse's technical skills of Tehran private hospitals is higher than the expected level. The average of the level of the head nurse's technical skills was obtained higher than the average level. Therefore, this hypothesis which is based on the proper level of head nurse's technical skills of Tehran private hospitals was verified. In other words, the level of head nurse's technical skills of Tehran private hospitals is appropriate. These result studies are parallel with the result studies of Vafaii [13] and Fatahi [14] and verify them.

The level of head nurse's humane skills of Tehran private hospitals is higher than the predicted level. The average of the level of the head nurse's humane skills was obtained higher than the average level. Therefore, this hypothesis which is based on the proper level of head nurse's humane skills of Tehran private hospitals was verified. In other words, the level of head nurse's humane skills of Tehran private hospitals is suitable. This study verifies the results study of Sellgren et al. [15], Park and Kim [16]. Sellgren considers the relation of head nurse's managerial skills and nurse employee's turnover intention according to the mediator variants of work atmosphere and occupational satisfaction in his study called "nurse employee's turnover intention: is management important?". The results showed that there is strong relation among managerial behavior, work atmosphere and occupational satisfaction and nurse employee's turnover intention. Occupational satisfaction has negative relationship with employees ' turnover intention.

Also, the level of head nurse's perceptional skills of Tehran private hospitals is higher than the expected level. The average of the level of the head nurse's perceptional skills was obtained higher than the average level. Therefore, this hypothesis which is based on the proper level of head nurse's perceptional skills of Tehran private hospitals was verified. The level of nurse employees ' turnover intention of Tehran private hospitals is low.

The average of the level of nurse employees' turnover intention was obtained lower than the average level. Therefore, this hypothesis which is based on being lower of the level of nurse employees ' turnover intention of Tehran private hospitals was verified. In other words, the level of nurse employees ' turnover intention of Tehran private hospitals is low. This result study verifies the result study of Raddaha et al. [17]. Raddaha et al. [17] consider the effective factors on the occupational satisfaction and nurse employees' turnover intention in hygienic and medicament part of Jordan in their study called "the occupational satisfaction of the Jordan's nurse employees and their turnover intention". The results showed that payment, promotion, presidency, supplementary advantages, compensations, operating procedures, colleagues, the nature and entity of the occupation and communication are the effective factors on occupational satisfaction and nurse employees' turnover. Also, occupational satisfaction affects nurse employees' turnover intention negatively and lower (reduce) the level of turnover.

Employees ' turnover is costly and threatening for the organization. When the good employees give up their work, organization must substitutes someone else and endures the costs of education and replacement, deposal and missing of production, disaffiliation with the costumers. The high rate of employees' turnover intention reduces the profiting and the interest of the company. US Department of Labor has assessed that one third of those costs belongs to the remuneration of a recently-employed person for backfilling of the blank and empty position [18]. Functional employees' turnover occurs when the employees with low efficiency are replaced with employees with high efficiency. In return, non-functional employees' turnover occurs when the employees with high efficiency are replaced with employees with low efficiency (Wallace) [19].

\section{Conclusion}

There was a relationship between head nurse's managerial skills and its aspects and decreasing of nurse employees ' turnover intention of Tehran private hospitals. So, nursing management can play a 
Citation: Nasiripour AA, Tabibi SJ, Mokhtari R (2014) The Relationship between Head-Nurse's Managerial Skills and Nurses' Turnover Intention in Private Hospitals. Health Care Current Reviews 2: 117. doi: 10.4172/2375-4273.1000117

significant role in decreasing of nurse employees` turnover intention by particular concern and attention of the ones who are responsible in nurse training. The head nurses are the leading managers of surveillance of the patients. So they must be dominant on management skills to be able to realize the most important aim of the hygienic and medicament organization which is surveillance of the patients and their recovery by the help and cooperation of the nurses who are under their control.

\section{Acknowledgments}

Our sincere thanks go to all the authorities and nursing staff of investigated private hospitals who kindly helped us to collect the data for this research.

\section{References}

1. Roghani M, Bahramzade $\mathrm{H}$, Bratali MR (2009) The Consideration of the Relation of the Degree of the Managerial Skills of the Managers and their Efficiency in the Organizations and the General and Governmental Offices of Bojnoord Province. Educational Research Paper 20: 159-183.

2. Goodarzi M, Hashem KC, Ehsani M (2004) Designing and Explanation of the Pattern of Triple Managerial Skills of the Managers of Physical Education Organization of Islamic Republic of Iran. Harekat Magazine 21: 51-78.

3. Mostafa A, Habib H, Farzad G (2010) Consideration of Triple Managerial Skills (Perceptional, Humane, Technical) of the Managers of the Offices of Physical Education of the Universities of the Country. Sportive Management.

4. Walls JE, Peachey JW (2011) Turnover intentions: Do leadership behaviors and satisfaction with the leader matter? Team Performance Management 17 23-40.

5. Javadin S, Reza S (2007) The Theories of Management and Organization. (2ndedn), Negah e Danesh Publication.

6. Jalil K, Bakhsh FM, Abolghasem HP, Ghiyasi M (2011) Consideration of Integration and Correlation of the Style of the Management of the Head nurses with the Tendency of the Nurses to the Continuity of Activities in Professional Parts of the Selected Hospitals of Medical Sciences of Shaheed Beheshti in 1388. Pajoohande Magazine 3: 112-116.

7. Tohfe MR (2010) The Relation of the Triple Managerial Skills and Utilizing of the Humane Powers in Electricity Distribution Company of Fars Province. Payam e Noor University of the Centre of Shiraz.
8. Anderson CA (1998) Management: skill function organization performance. (2ndedn), McGraw Hill.

9. Amir YNA (2004) The Consideration of the Degree of the Managerial Skills of the Managers of the Guidance Schools and High Schools and its Relation with the Operation of the Teachers of the Area of Falavarjan in 1382-1383. Azad University of the Branch of Khorasegan

10. Saeed AZ (2004) Assessment of the Managerial Skills of the Research Managers of the Medical Science Universities for Determination of the Educational Goal. Medical Science Faculty Magazine of Medical Science University of Gilan 49: 86-96

11. Azad AM (2002) Consideration of the Managerial Skills and its Relation with the Operation of the General Managers of Ilam Province. Governmental Management Training centre.

12. Demir R, Soderman S (2007) Skills and complexity in management of IJVs: Exploring Swedish managers' experiences in China. International Business Review 16: 229-250.

13. Vafaii M (2002) Consideration of the Effect of the Managerial Skills (Technical, Humane, Perceptional) of the Managers on the Decreasing of the Occupational Fatigue of the Employees in Investment Company of Chemical Industries of Iran. Governmental Management Training centre.

14. Fatahi MA (2002) Consideration of the Degree of the Managerial Skills of the Managers of the Profiting and Non-profiting Branches of Sepah Bank of Tehran. Governmental Management Training centre.

15. Sellgren S, Ekvall G, Tomson G (2007) Nursing staff turnover: does leadership matter? Leadersh Health Serv 20: 169-183.

16. Park JS, Kim TH (2009) Do types of organizational culture matter in nurse job satisfaction and turnover intention? Leadersh Health Serv 22: 20-38.

17. Raddaha AHA, Alasad J, Albikawi ZF, Batarseh KS, Realat EA, et al. (2012) Jordanian nurses' job satisfaction and intention to quit. Leadersh Health Serv 25: 216-231.

18. Sexton RS, McMurtrey S, Michalopoulos JO, Smith AM (2005) Employee turnover: A neural network solution. Computers \& Operations Research 32 2635-2651.

19. Wallace JG (2009) An Empirical Analysis of Dysfunctional and Functional Voluntary Employee Turnover. A dissertation submitted in partial fulfillment of the requirements for the Degree of Doctor of Philosophy in Applied Management and Decision Sciences, Walden University. 